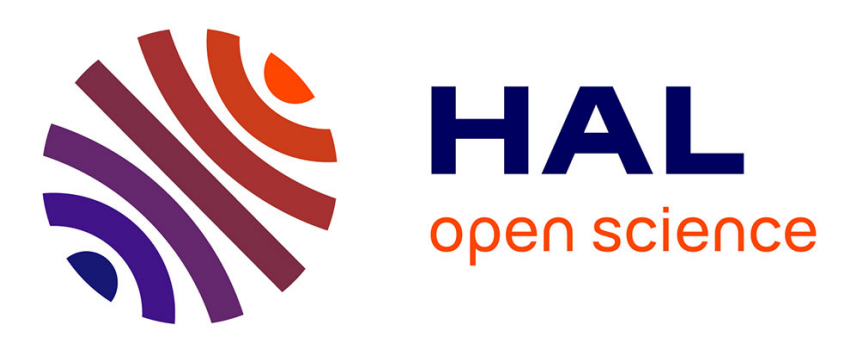

\title{
Dynamic Constitutional Frameworks as Antibacterial and Antibiofilm Agents
}

Andrei Diaconu, Tom Coenye, Mihail Barboiu, Stéphane Vincent

\section{To cite this version:}

Andrei Diaconu, Tom Coenye, Mihail Barboiu, Stéphane Vincent. Dynamic Constitutional Frameworks as Antibacterial and Antibiofilm Agents. Angewandte Chemie International Edition, 2021, 60 (41), pp.22505-22512. 10.1002/anie.202109518 . hal-03410233

\section{HAL Id: hal-03410233 https://hal.science/hal-03410233}

Submitted on 1 Nov 2021

HAL is a multi-disciplinary open access archive for the deposit and dissemination of scientific research documents, whether they are published or not. The documents may come from teaching and research institutions in France or abroad, or from public or private research centers.
L'archive ouverte pluridisciplinaire HAL, est destinée au dépôt et à la diffusion de documents scientifiques de niveau recherche, publiés ou non, émanant des établissements d'enseignement et de recherche français ou étrangers, des laboratoires publics ou privés. 


\title{
Dynamic Constitutional Frameworks as antibacterial and antibiofilm agents
}

\author{
Andrei Diaconu, ${ }^{[a, c]}$ Tom Coenye, ${ }^{[d]}$ Mihail Barboiu,,$^{[b]^{*}}$ Stéphane P. Vincent ${ }^{[a]^{*}}$
}

[a] A. Diaconu, Prof. Dr. S. Vincent,

Faculty of Science, University of Namur,

Rue de Bruxelles, 61, Namur, Belgium.

E-mail: stephane.vincent@unamur.be

[b] Dr. M. Barboiu,

Institut Européen des Membranes,University of Montpellier, ENSCM, CNRS,

Place Eugène Bataillon, CC 047, F-34095, Montpellier, France.

Email: mihail-dumitru.barboiu@umontpellier.fr

[c] A. Diaconu

Center of Advanced Research in Bionanoconjugates and Biopolymers

Petru Poni” Institute of Macromolecular Chemistry of Romanian Academy,

41A, Aleea Gr. Ghica Voda, lasi, Romania.

[d] Prof. Dr. Coenye

LPM Laboratory of Pharmaceutical Microbiology, Ghent University,

Ottergemsesteenweg 460, B-9000 Ghent, Belgium

Supporting information for this article is given via a link at the end of the document. ((Please delete this text if not appropriate))

Abstract: Dynamic Constitutional Frameworks (DCFs) were synthesized and screened for biofilm inhibition or disruption. They are composed of a trialdehyde core reversibly linked to a diamine PEG connector and to a variety of neutral, anionic or cationic heads, to generate a library of DCFs to generate multivalent dendritic architectures in the presence of Pseudomonas aeruginosa and Staphylococcus aureus. The best DCFs were always polycationic and the nature of the cationic heads significantly impact the antibiofilm activity. The best antibiofilm activity was observed for DCF3B, displaying a polyethyleneimine head. Interestingly, a simple inactive guanidinium functional head, strongly inhibited biofilm growth when assayed as a multivalent DCF3C. Using a more advanced in vitro biofilm model of chronic wound infection, DCF3C was found significantly superior than all other DCFs. These results demonstrate 1) the versatility and effectiveness of DCFs as low cost and efficient systems for antibiofilm disruption 2) the efficiency of dynamic chemistry as a discovery technology.

\section{Introduction}

Biofilms are communities of microbial cells that are embedded in a self-produced extracellular polymeric matrix and are either attached to a surface or occur as non-surface attached aggregates. ${ }^{[1]}$ Biofilms are frequently encountered in nature; they can be beneficial (e.g. waste water treatments) or have a negative impact, e.g. when causing fouling in industrial settings or when they form on medical devices like catheters. ${ }^{[2]}$ Microorganisms in biofilms are protected against the activity of antibiotics ${ }^{[3]}$ and a lot of efforts are being made to develop novel compounds with antibiofilm activity. ${ }^{[4]}$

Although many bactericidal molecules or materials have been developed to date, only few inhibit biofilm formation. While a bactericide is a molecule or a material that kills bacteria, a biofilm formation inhibitor blocks bacterial attachment to surfaces and/or formation of aggregates. Molecules or materials that can disturb the structure of a mature biofilm, reduce or remove its biomass are named biofilm disruptors, and are also very difficult to develop or design. [5]

A wide range of nanofabrication techniques and materials have been used to generate antibacterial materials based on nanopillars that induce mechanical stretching of the bacterial membrane, leading to bursting of the cells upon contact. ${ }^{[6]}$ Enzymatic degradation of the extracellular matrix (including extracellular DNA) produced by cells in a biofilm can weaken its structure and can lead to dispersal of cells from the biofilm. However, bacteria produce extracellular exoenzymes that apparently prevent excessive degradation of the biofilm matrix. ${ }^{[6 c}$ ${ }^{7]}$ By interfering with these self-controlling mechanisms, specific molecular binders could represent a potent strategy for controlling biofilm growth. Positively charged multivalent platforms ${ }^{[6 b, 8]}$ have been used as inhibitors for biofilm formation, as many components of the biofilm are negatively charged in physiological conditions. ${ }^{[9]}$ For instance, Haag et al. synthesized multifunctional zwitterionic pillar[5]arenes, which formed self-assembled positively charged nanoaggregates displaying antibacterial and biofilm disrupting activities. ${ }^{[6]}$

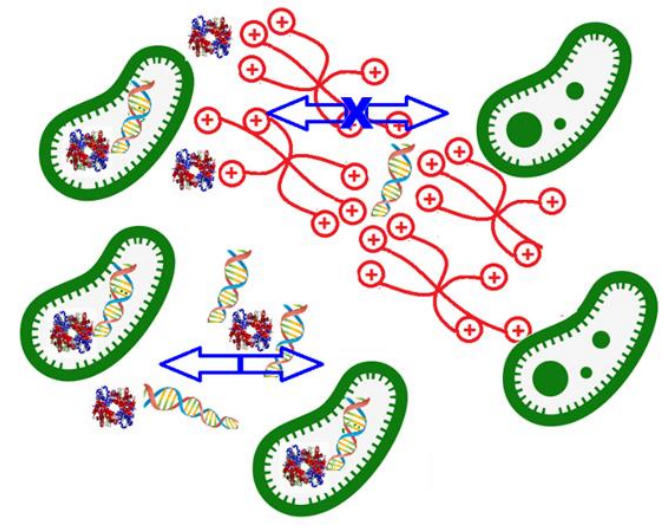

Figure 1. Dynamic Constitutional Frameworks (in red) acting as potentia disruptors of bacterial biofilms as adaptive recognition platforms and effective barriers against the diffusion of biomolecules (i.e. DNA, proteins, etc.) between different bacteria (in green) of the biofilm community. 


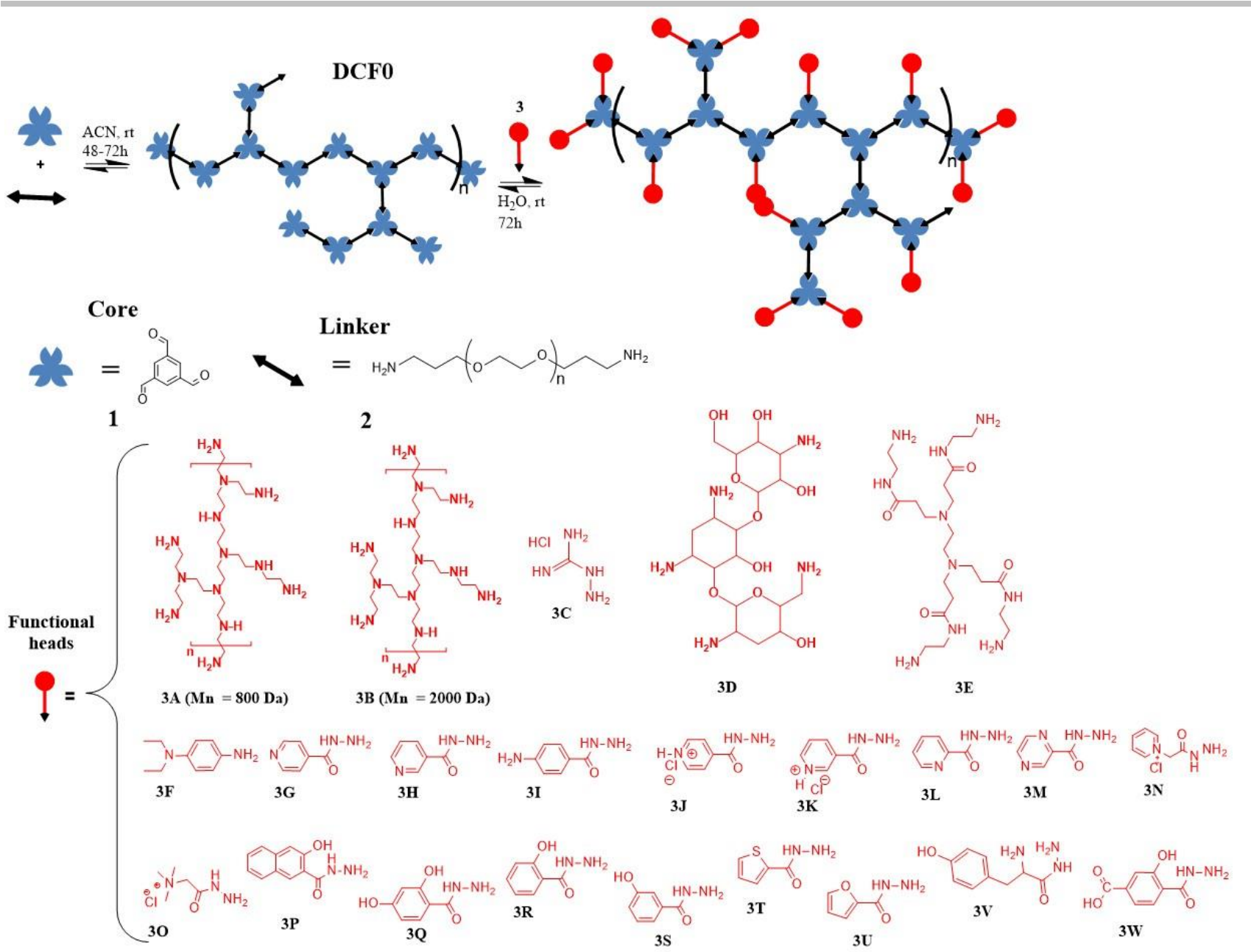

Figure 2 - Synthesis of DCFs combining 1,3,5- benzenetryaldehyde core 1, (blue) with PEG connector 2, (black) and functional heads $\mathbf{3}$, (red) in water to generate DCFs. The names of the synthetized DCFs take into account both the functional module $3 \mathrm{X}$ and its molarity compared to 1 and 2 . For instance, for functional module 3A, we used 4 different molar ratios 1:3, and their corresponding names are: DCF 3A1.5, DCF 3A2.0, DCF 3A2.5 and DCF 3A3.0. (See Table 1SI in supporting information).

Dynamic constitutional frameworks (DCFs) are adaptive 3D dynamic polymeric - dynameric networks that have been used as multivalent platforms for DNA recognition and transfection as well as other biomedical applications. ${ }^{[10]}$ Linear or cross-linked connecting building blocks and polyfunctional core centers, linked together by reversible bonds were used to form cross-linked 3D scaffolds on which cationic or $\mathrm{H}$-bonding head building blocks have been attached as terminal components, giving the DCF scaffolds the ability to bind proteins or nucleic acids. Importantly, these species display low cytotoxicity with eukaryotic cells. ${ }^{[13 \mathrm{~b}]}$

The dynamic covalent and supramolecular bonds play an important role in the ability to adaptively implement reversible and constitutional rearrangements of the components within DCFs, controlling their highly competitive multivalent synergetic interactions with the components of the biofilm in order to create effective networks for biofilm disruption (Figure 1).

In this study we are targeting two biofilm producing bacteria, Pseudomonas aeruginosa and Staphylococcus aureus. $P$. aeruginosa is a Gram-negative opportunistic human pathogen involved in a wide variety of infections, including respiratory, urinary tract and skin infections ${ }^{[9,11]} S$. aureus is a Gram-positive opportunistic human pathogen that can cause a range of illnesses, from minor skin infections to life-threatening diseases such as pneumonia, meningitis, osteomyelitis and endocarditis. It is frequently associated with hospital-acquired infections and is often the cause of wound infections following surgery.

In the present study, we propose an unprecedented and easily processable strategy based on dynamic constitutional chemistry for the self-construction of DCFs which are screened for their antibacterial and antibiofilm activity. We use simple building blocks and an easy parallel screening of complex mixtures via cooperative and competitive binding effects. This approach allows the rapid identification of potential highly active candidates, generated from a large set of building blocks. The methodology to generate DCFs is based on imine bond formation and exchanges between three types of building blocks (Figure 2): i) The core center which is the connection point of the network $(1,3,5$ benzenetrialdehyde, BTA); ii) The poly-(ethyleneglycol)-bis(3aminopropyl) terminated-PEG is used as the cross-linking connector of the network and as enhancer of the solubility in water; iii) The amino or acyl hydrazone functional heads are the most important molecular subunits, that determine the interactional affinity and the selectivity of the DCFs for the biological targets. 


\section{Results and Discussion}

In the present study, the trialdehyde BTA core $\mathbf{1}$ and the PEG diamine linker 2 are present in all DCFs in a 1:1 molar ratio, leaving free aldehydes for further reactions with amino or acylhydrazone functional heads $\mathbf{3}$, to form DCFs in water (Figure 2). Beside cationic functional heads 3 , we also selected several neutral ones that may bind proteins playing a key role in biofilms. For instance, lectins LecA and LecB selectively bind uncharged molecules and are important in the virulence and the biofilm formation of $P$. aeruginosa ${ }^{[12]}$ Treatment of 1 with $2(1: 1, \mathrm{~mol}: \mathrm{mol})$ in acetonitrile (r.t., 48-72h) afforded, as previously reported, ${ }^{[13]}$ two mixtures of linear and cross-linked neutral DCF0 assembled via reversible amino-carbonyl/imine chemistry (Figure 2). Importantly, the ${ }^{1} \mathrm{H}$-NMR spectra, recorded in $\mathrm{CD}_{3} \mathrm{CN}$ and $\mathrm{D}_{2} \mathrm{O}$ are similar and remain unchanged for months at neutral $\mathrm{pH}$. As previously observed, the PEG chains may have a protecting effect against the hydrolysis of the imine bonds, favouring the imine formation, leading to linear and crosslinked species in solution. ${ }^{[13]}{ }^{1} \mathrm{H}-\mathrm{NMR}$ spectra show the presence of unreacted aldehydes in the resulting DCF0. DCF0 (2 mg/mL of 1) was further reacted in water with functional heads $3 \mathrm{~A}-\mathrm{W}$ at a molar ratio 1: $2: 3 \mathrm{~mol}: \mathrm{mol}: \mathrm{mol}$ of 1:1:2 generating the final DCF3A-DCF3W (Figure 2, see Supplementary information for the synthetic details). Their ${ }^{1} \mathrm{H}$ NMR spectra are reminiscent with the formation of completely condensed frameworks with an optimal molar ratio of $1: 1: 2$, that will be used for biofilm inhibition screening. The molar ratio between the functional heads and the core subcomponents will be further optimized after the biological screening

To gain insight into the morphology and aggregation of DCFs in aqueous solution we investigated their self-assembly behaviours by Dynamic Light Scattering (DLS) and zeta potential experiments (Figure 3). ${ }^{[14]}$ When dissolved in water, the measured hydrodynamic diameters show that most of the DCFs are highly dispersed, suggesting that they are not aggregating in solution, as expected for hydrophilic charged species. However, some particle aggregation can be observed in several cases: a) DCF3P (polydispersity index $[P D I]=0.256$ ) and DCF3Q $(\mathrm{PDI}=0.157)$ have a good $\mathrm{PDI}$ with an average diameter of nanoparticles of 122.0 and $36.5 \mathrm{~nm}$, respectively. b) DCF3H $(\mathrm{PDI}=0.350)$ and DCF3S $(\mathrm{PDI}=0.421)$ have a high $\mathrm{PDI}$ with an average diameter of nanoparticles of $400.0 \mathrm{~nm}$ and $2000.0 \mathrm{~nm}$ respectively, while DCF3K, DCF3V and DCF3W show a high PDI and a broad distribution of the diameter of nanoparticles, indicating that several groups of nanoparticles of different dimensions are present in aqueous solution (Figure $\mathbf{3 b}$ ).

Zeta potential experiments for which a large distribution of potential values was observed (Figure 3c) suggest that most of the DCFs have a low colloidal stability. These data are in agreement with the DLS analysis, since the aggregation processes of DCFs results in large structures and indicates that the hydrophilic PEG connectors within the DCFs participate in the charge distribution effect in aqueous solution. The dispersion of DCFs within biofilm may represent an advantage as they cover large surfaces within biofilm space as a source of enhanced activity.

The non-aggregating behaviours observed in aqueous solution by DLS and zeta potential data were confirmed by Atomic Force Microscopy (AFM) experiments. The AFM micrographs (Figure 4) show a large variety of morphologies: a) the formation of nanoparticles of DCFO confirm the formation of highly polydisperse interconnected aggregates from $10 \mathrm{~nm}$ to $150 \mu \mathrm{m}$. (Figure 4a); b) dendritic structures have been observed for dried solid samples of DCF3A (Figure $\mathbf{4 b}$ ), while the PDI higher than 0.7 in the DLS analysis is confirming the occurrence of highly dispersed PEI800 heads in water; c) replacing PEI800 with PEI2000 in DCF3B results in spherical particles with diameter from $\sim 100-200 \mathrm{~nm}$ to $5-10 \mu \mathrm{m}$ and height up to $95 \mathrm{~nm}$ are observed by AFM (Figure 4c), while in solution particles with polydisperse size can be observed by DLS; d) different spherical, rod-like, and dendritic $100 \mathrm{~nm}$ to $15-20 \mu \mathrm{m}$ interconnected particles can be observed for DCF3F (Figure 4d), confirming the large distribution observed by DLS; e) DCF3J has a complex size distribution with highly aggregated particles from $100 \mathrm{~nm}$ to 100 $\mu \mathrm{m}$ (Figure 4e); f) AFM analysis of DCF3V shows a homogenous distribution of particles from 10 to $300 \mathrm{~nm}$, with a height up to 38 $\mathrm{nm}$.
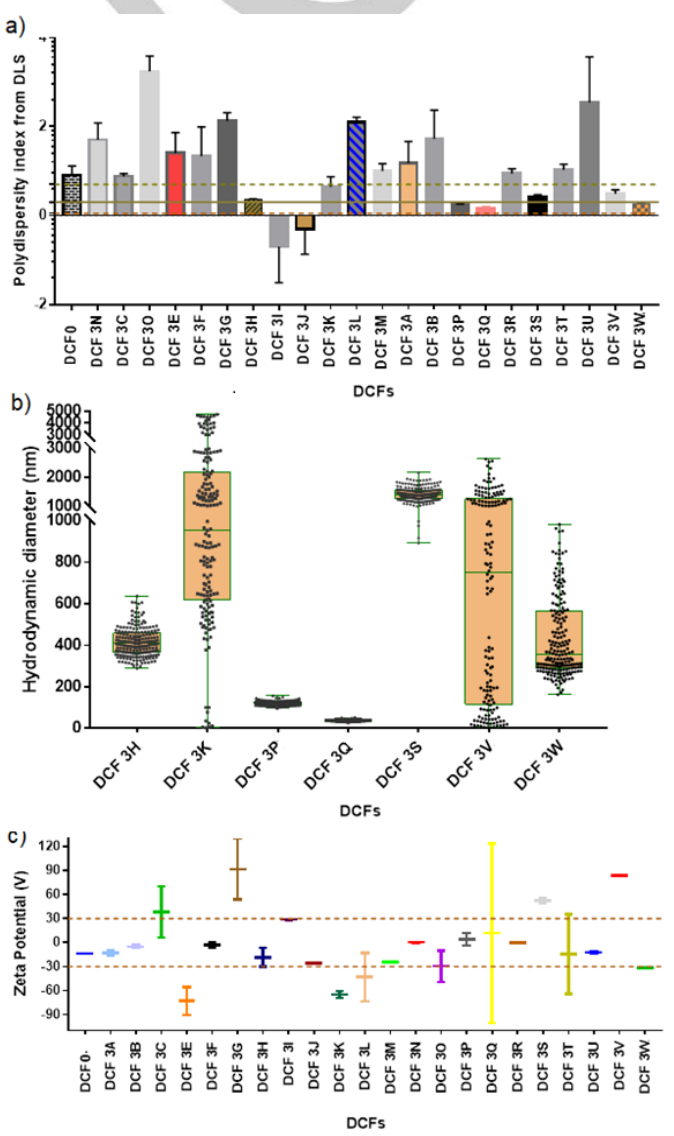

Figure 3 - DLS analysis a) Polydispersity index indicating the dispersity of the samples: values higher than 0.7 indicate that sample has a very broad size distribution and b) Hydrodynamic diameter (PDI $=0.05$ and 0.7 ) showing several particle size dimension with different low and high distributions and c) Zeta potential-ZP of the DCFs samples, indicating the stability of colloidal samples related to electrically stabilized colloids for high ZP values or low dispersed flocculate particles for low ZP values.

The AFM data show that the studied DCFs present unpredictable highly aggregated structures in the solid state (Figure 4). These diverse morphological behaviours confirm the conclusions of DLS studies which lay to the formation of the extended DCF networks having a large polydispersity in solution. The dimensions of DCF particles strongly depend on their solubility which is mostly dictated by the nature of the terminal heads. 
The antibacterial and antibiofilm activities of the library of DCFs were subsequently tested to identify the best combinations and compositions. Our methodology was to 1) screen the library at a single DCF components' ratio 1:1:2 using a standard $P$.<smiles>CC=NCCCOCCN=Cc1cc(C=O)cc(C=O)c1</smiles>

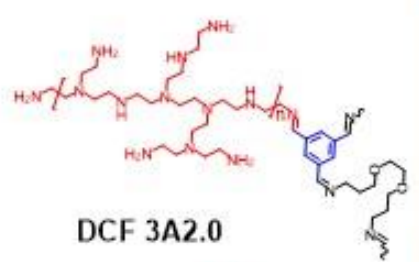

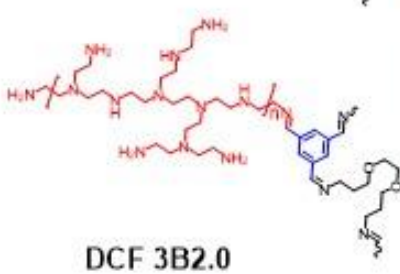

DCF 3B2.0<smiles>CC=Nc1cc(C=NCCCOCCC=NCC)cc(C=Nc2ccc(N(CC)CC)cc2)c1</smiles>

DCF 3F2.0<smiles>C/C=N\CCCOCCC/N=C\c1cc(/C=N/N=C/[O-])cc(/C=N/NC(=O)c2ccncc2)c1</smiles>

DCF 3J2.0

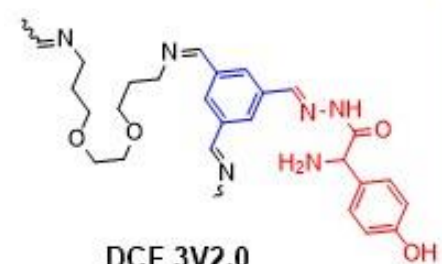

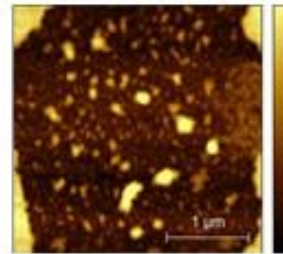
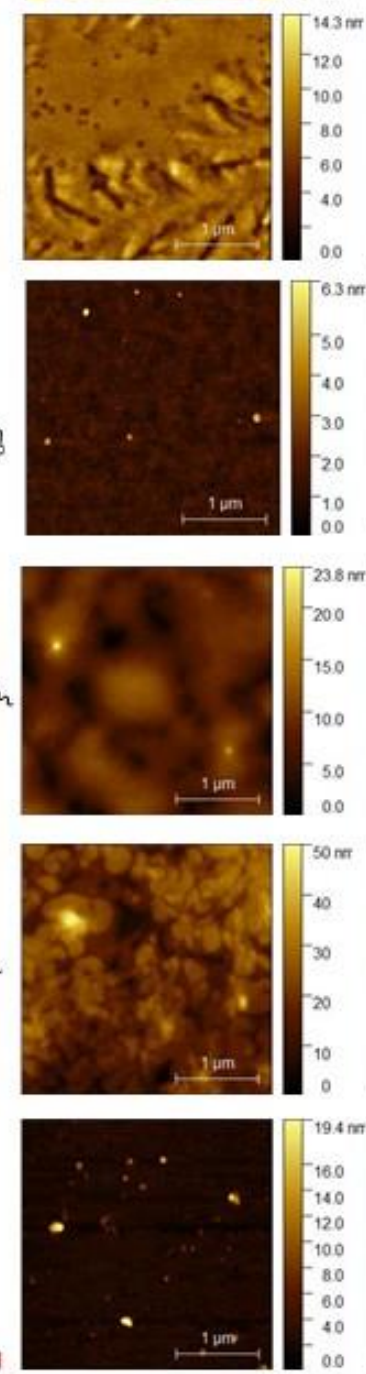

aeruginosa biofilm assay to identify the best functional modules; 2) optimize the components ratio on the best DCFs; 3) characterize the antibiofilm activity using three distinct biological assays; and 4) test the antibiofilm activity on S. aureus.
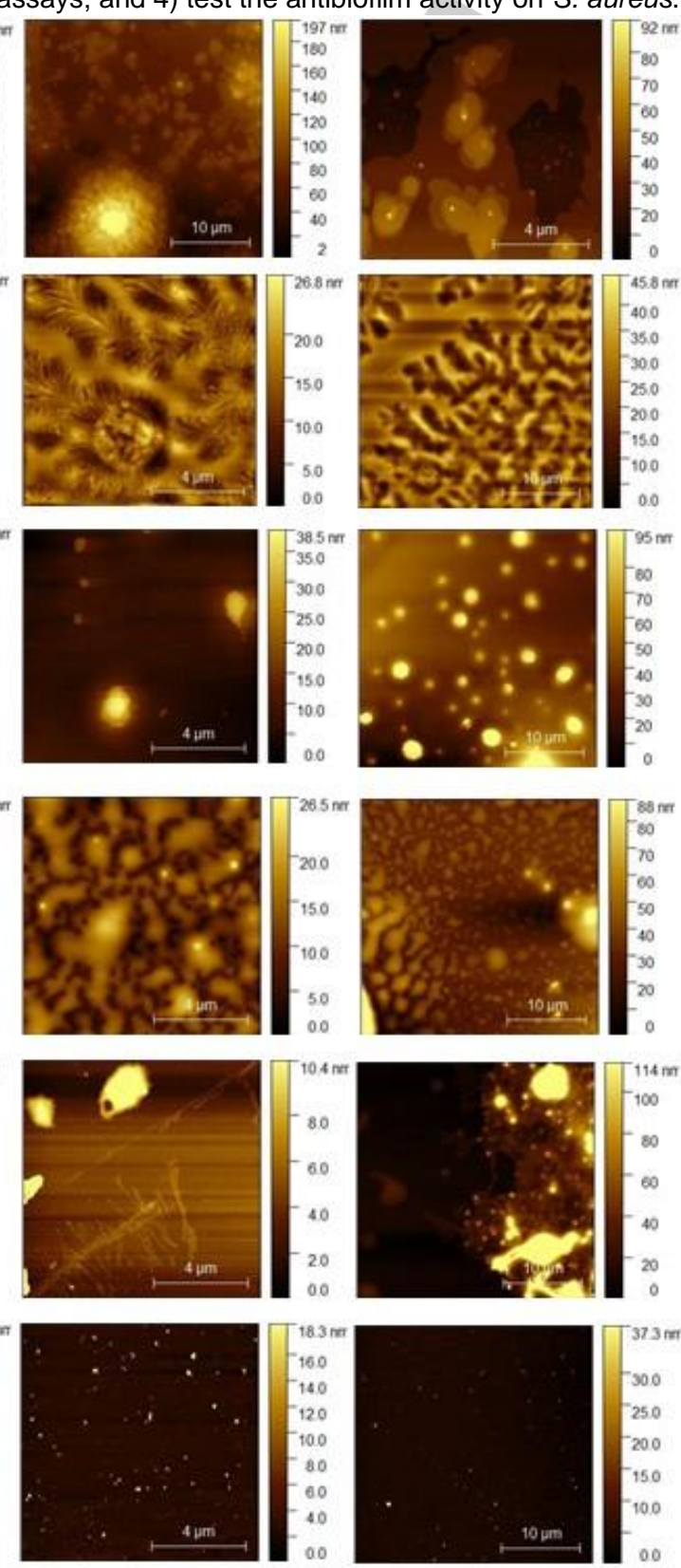

Figure 4 - The AFM micrographs of DCF0, DCF3A, DCF3B, DCF3F, DCF3J and DCF3V.

The assay used to identify the active DCFs was the standard crystal violet biofilm biomass staining of biofilms grown in 96-well microtiterplates. [2a, 15] Bacterial biofilms were grown in the presence of increasing concentrations of DCFs in 96-well plates. After rinsing the plates, the remaining biofilm biomass was stained with crystal violet and the amount of biofilm biomass was directly assessed by UV-Vis absorbance. Tobramycin 3D was used as a positive control. ${ }^{[9,11,16]}$

The antibiofilm activities of the best DCFs against $P$. aeruginosa biofilms are shown in Figure 5 (See Figure S6, Supporting Information, for the entire series). DCF containing cationic functional heads $3 \mathbf{A}, \mathbf{3 B}$ and $\mathbf{3 C}$ have the strongest antibiofilm activities while DCF containing functional heads $\mathbf{3 F}, \mathbf{3 V}$ and $\mathbf{3 W}$ have lower activities. All the other functional heads screened in this DCF library did not provide any antibiofilm activity. This initial screening clearly evidenced that both the nature (ammoniums, pyridiniums, guanidiniums etc...) and the structure of the functional heads play a central role in the observed antibiofilm activities. Transamination reactions might occur at the surface of the cell membranes. As we already mentioned, previous studies demonstrated that the presence of cationic heads and PEG connectors are useful for the formation of cyto-friendly DNA polyplexes and DCFs as DCF3A and DCF3B are well tolerated by cells. ${ }^{13 b}$ 
The fact that the very best DCFs have been identified within the subgroup of cationic functional heads can potentially be explained by the fact that $P$. aeruginosa biofilm cells are embedded in negatively charged polymeric biomolecules like alginate ${ }^{[9,}$ 17], other exopolysaccharides or extracellular nucleic acids. ${ }^{[18]}$ All these negatively charged molecules could thus strongly bind the positive charges of the functional heads, thus giving a better biofilm inhibition compared with the neutral and negatively charged DCFs.

Having identified the best functional modules, the next step was to evaluate whether the relative ratios of each component of the DCFs would affect their capability of inhibiting biofilm formation.
We prepared new DCFs containing different amounts of functional heads $\mathbf{3 A}, \mathbf{3 B}$ and $\mathbf{3 C}$ at four molar ratios $(1.5,2.0,2.5$ and 3 ) relative to the core BTA 1 (Figure 6, plots $A, B$, and $C$ for functional modules 3A, 3B, 3C, respectively). As for the initial DCF library, the molar ratio between core 1 and linker 2 was 1:1. The general trend was that increasing the proportion of cationic functional module relative to 1 increased the antibiofilm activity. For modules $\mathbf{3 A}$ and $\mathbf{3 C}$ the ratio 2.5 gave the best inhibition results. At this ratio the concentration of $31 \mu \mathrm{M}$ (relative to 1 ) gives a biofilm inhibition higher than $50 \%$. This series of experiments indicate that the charge density at the surface of these dendritic materials play an important role in the antibiofilm activity.

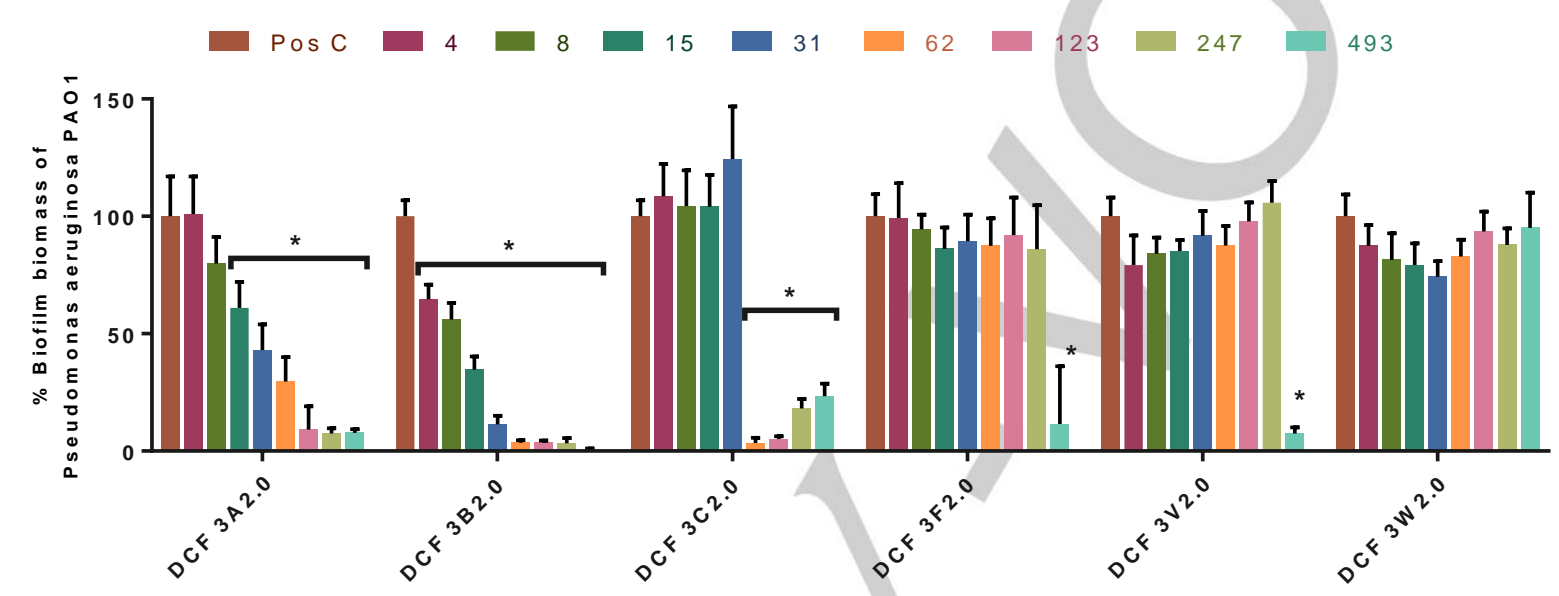

Figure 5 - Biofilm biomass evaluated after the treatment of $\sim 5 \times 10^{6} \mathrm{CFU}$ of $P$. aeruginosa PAO1 with positively charged DCFs at increasing concentrations. The concentration range is $4-493 \mu \mathrm{M}$ of 1 for all DCFs. Untreated bacteria are used as positive control (Pos C set to 100\%). The experiments were performed a single time with 3 biological replicates each with 2 technical replicates. Data shown are average, error bars indicate standard deviation. * ANOVA with a Dunnett post hoc test statitical test with $\mathrm{P}>0.0001$.

As a control, we also measured the antibiofilm activity of the functional reference heads (Figure 6D). Functional heads 3A and 3B show antibiofilm activity on their own. Interestingly, functional module $\mathbf{3 C}$ does not show any antibiofilm activity by itself while its DCFs show powerful biofilm inhibition. Noteworthy, the control 1:1 mixture of core BTA 1 and linker PEG diamine 2 without functional module (compound named DCF0) did not display any antibiofilm activity. Globally, the best DCFs present an antibiofilm activity at concentrations of 2 to $123 \mu \mathrm{M}$ of 1 (or $5 \mu \mathrm{g} / \mathrm{mL}$ to $1 \mathrm{mg} / \mathrm{mL}$ for the whole material).

To further quantify the antibiofilm activity, the concentrations at which the increase of biofilm biomass is inhibited by at least $50 \%$ $\left(\mathrm{BBIC}_{50}\right)$ were determined for the best DCFs and their corresponding functional modules (Table 1). As usual in microbiology and material sciences, we specified the mass concentrations $(\mu \mathrm{g} / \mathrm{mL})$ of the whole material. To allow comparison of the molar concentrations of the different DCFs we also expressed them as the $\mu$ molar concentration $(\mu \mathrm{M})$ of $\mathbf{1}$ that is present in the DCF. We also determined the minimal biofilm eradication concentration $\left(\mathrm{MBEC}_{50}\right.$, Table 1$)$, which is a measure of the ability of a material to disrupt an existing biofilm. MBEC 50 represents the lowest concentration of DCF that eradicates at least $50 \%$ of the biofilm biomass of a mature biofilm (supplementary information for detailed protocol). Here, bacteria were allowed to form biofilm during 24 hours, and after rinsing the planktonic bacteria, fresh culture medium and increasing concentrations of DCFs were added and incubated for another 24 hours. The remaining biofilm biomass was compared with the control experiment (untreated PAO1 biofilm formation after 24h). In general, $\mathrm{MBEC}_{50}$ values were found to be in the same range as the $\mathrm{MBIC}_{50}$ values.

Globally, the three most-active DCFs are DCF3A, DCF3B and DCF3C. Their antibiofilm activities are in the same range but DCF3B had a better profile, especially for its ability to eradicate a pre-established biofilm. However, the most remarkable result of the whole series is the fact that DCF3C displays good biofilm inhibition properties despite the fact that its subcomponents have neither antibiofilm nor bactericidal activities.

The results obtained are encouraging as the activity range obtained against $P$. aeruginosa is similar to the literature data on positively charged pillararenes, bridged bicyclic peptides or glycopeptide dendrimers, ${ }^{[8 b,}$ 19] while the synthetic work to generate our DCF materials is significantly more simple and less expensive, thanks to the dynamic chemistry approach.

To assess whether this pronounced antibiofilm activity is due to bacterial growth inhibition, we determined the $\mathrm{MIC}_{50}$ of the most active DCFs (Table 1). The $\mathrm{MIC}_{50}$ is the minimal concentration that reduces the growth of planktonic bacteria with at least $50 \%$ compared to untreated controls. 3A and 3B and DCF3B have a $\mathrm{BBIC}_{50}$ that is lower than the $\mathrm{MIC}_{50}$ which indicates that this material might prevent $P$. aeruginosa biofilm formation at concentrations that do not inhibit growth. 
A

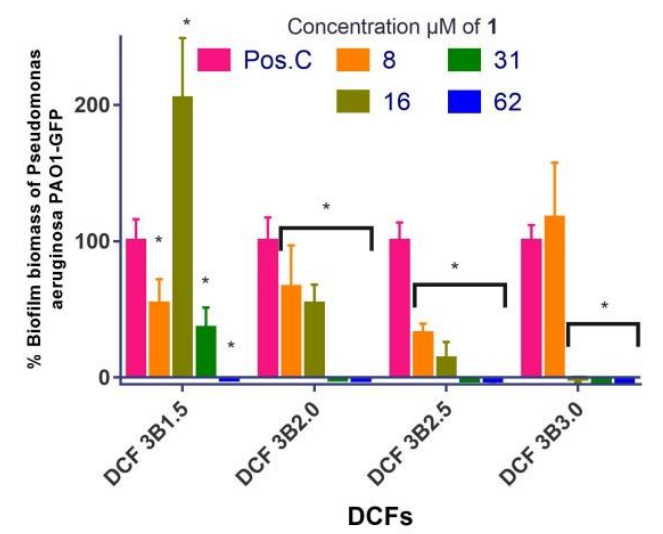

C

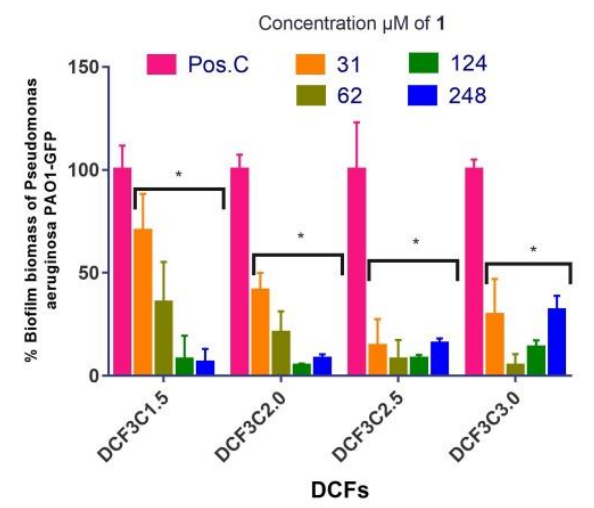

B

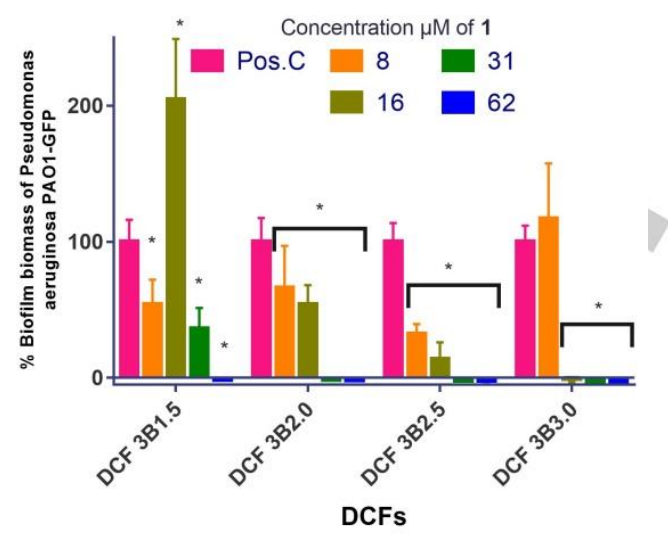

D

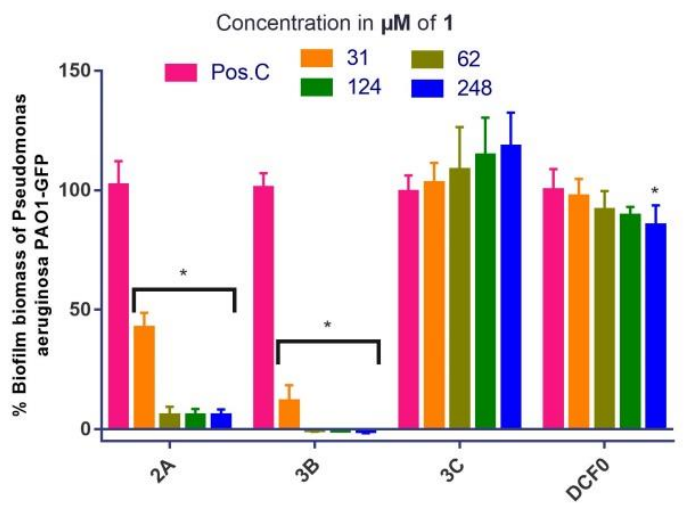

Figure 6 - Biofilm biomass evaluated after the treatment of $\sim 5 \times 10^{6} \mathrm{CFU}$ of $P$. aeruginosa PAO1 with DCFs composed of variable functional module ratio (1.5; 2.0; 2.5; 3.0 relative to 1 ) at increasing DCFs concentrations and compared to the untreated controls Pos.C; A) DCFs with functional module 3 A B) DCFs with functional module 3B C) DCFs with functional module 3C D) functional modules alone and DCF0 (the network DCF0 between 1 and 2 at a 1:1 molar ratio) at the concentration range of the DCFs. The experiments were repeated 2 times, each with 6 technical replicates. ${ }^{*}$ ANOVA with a Dunnett post hoc test statitical test with $\mathrm{P}<0.0001$.

Table 1 - MIC50, MBIC 50 and $\mathrm{MBEC}_{50}$ values for the most active DCFs and functional modules against $P$. aeruginosa PAO1

\begin{tabular}{|c|c|c|c|}
\hline DCF & $\mathrm{BBIC}_{50}$ & $\frac{\mathrm{MBEC}_{50}}{\mu \mathrm{g} \cdot \mathrm{mL}^{-1}(\mu \mathrm{M} \text { of } \mathbf{1})}$ & $\mathrm{MIC}_{50}$ \\
\hline DCF 3A2.0 & $201(62)$ & 808 (246) & $201(62)$ \\
\hline $3 A$ & $49.3\left(62^{a}\right)$ & $98.7\left(123^{\mathrm{a}}\right)$ & $98.7\left(123^{a}\right)$ \\
\hline DCF 3B2.0 & $87.3(15)$ & $174.6(62)$ & $174.6(32)$ \\
\hline 3B & $62\left(31^{a}\right)$ & $123\left(62^{a}\right)$ & $123\left(62^{\mathrm{a}}\right)$ \\
\hline DCF 3C2.0 & $116(62)$ & & $116(62)$ \\
\hline $3 C$ & & & $-b$ \\
\hline $\begin{array}{l}\text { DCF 3D2.0 } \\
\text { (control) }\end{array}$ & $10(3.9)$ & $20(7.8)$ & 5 (1.92) \\
\hline $\begin{array}{l}\text { 3D (control } \\
\text { antibiotic) }\end{array}$ & $3.6\left(7.8^{a}\right)$ & $3.6\left(7.8^{a}\right)$ & $1.8\left(3.9^{a}\right)$ \\
\hline DCF 3F2.0 & & $\mathrm{nt}^{\mathrm{d}}$ & $-c$ \\
\hline DCF 3V2.0 & $1013(493)$ & $-c$ & $1013(493)$ \\
\hline DCF $3 W 2.0$ & & $\mathrm{nt}^{\mathrm{d}}$ & $-c$ \\
\hline
\end{tabular}

a) Concentration $(\mu \mathrm{M})$ in pure functional module b) value higher than 1 $\mathrm{mM} \mathrm{c}$ ) value higher than $0.5 \mathrm{mM} \mathrm{d}$ ) $\mathrm{nt}$ - not tested;
Table $2-\mathrm{MIC}_{50}$ and $\mathrm{MBIC}_{50}$ results for active DCFs and functional module against $S$. aureus Mu50.

\begin{tabular}{|c|cc|}
\hline \multirow{2}{*}{ DCFs } & $\mathrm{BBIC}_{50}$ & $\mathrm{MIC}_{50}$ \\
\cline { 2 - 3 } & $\mu \mathrm{g} \cdot \mathrm{mL}^{-1}$ of the whole material $(\mu \mathrm{M}$ of 1) \\
\hline DCF 3A2.0 & $402(123)$ & $805(247)$ \\
3A & $-\mathrm{b}$ & $789\left(986^{\mathrm{a}}\right)$ \\
\hline DCF 3B2.0 & $349(62)$ & $349(62)$ \\
3B & $-\mathrm{b}$ & $246\left(123^{\mathrm{a}}\right)$ \\
\hline DCF 3C2.0 & $986(>493)$ & $-\mathrm{b}$ \\
\hline 3C & $-\mathrm{b}$ & $5125(1973)$ \\
\hline DCF 3D2.0 & $>1973$ & $1850(3957)$ \\
\hline 3D (contro1) & $1850(>3957)$ & $982(493)$ \\
\hline antibiotic) & $982(493)$ & $506(247)$ \\
\hline DCF 3F2.0 & $-\mathrm{c}$ & $-\mathrm{c}$ \\
\hline DCF 3V2.0 & $-\mathrm{c}$ & \\
\hline DCF 3W2.0 & & \\
\hline
\end{tabular}

a) Concentration $(\mu \mathrm{M})$ in pure functional module b) value higher than $1 \mathrm{mM} \mathrm{c}$ ) value higher than $0.5 \mathrm{mM}$. 
To shed light on the origin of the antibiofilm activity, growth curves have been measured in presence of $0.63 \mu \mathrm{g} / \mathrm{mL}, 10 \mu \mathrm{g} / \mathrm{mL}$ and $80 \mu \mathrm{g} / \mathrm{mL}$ of compounds DCF3A, DCF3B and DCF3C (ESI, Figures S14-S16). With a full growth inhibition at $10 \mu \mathrm{g} / \mathrm{ml} \mathrm{DCF}$ 3C proved to be the most potent material for this assay (DCF3C > DCF3B > DCF3A). Our data suggest that the antibiofilm effect of the three DCFs is at least partially due to their concentrationdependent inhibition of bacterial growth. Such a feature has been already observed among antibiofilm agents that often proceed through bacterial killing ${ }^{[6 b,}{ }^{20]}$. In general the $\mathrm{MBEC}_{50}$ concentrations are equal or higher than the $\mathrm{MIC}_{50}$ or $\mathrm{BBIC}_{50}$ for all the DCFs, except for DCF 3C. This result was not surprising as it is clear from the literature that eradicating a pre-existing biofilm is more difficult than inhibiting biofilm formation.

Next, we evaluated the antibiofilm properties of the best materials using an in vitro biofilm model of chronic wound infection. ${ }^{[21]}$ In brief, biofilms were grown on an artificial dermis and the antibiofilm properties of DCF 3A-3C were evaluated by CFU (colony forming units) numbering (See SI Figure SI17). Interestingly, DCF 3C was from far the most potent material with this assay (DCF3C > DCF3B > DCF3A), a result in good correlation with the growth inhibition experiments described above.

To broaden the scope of this investigation, we also tested the best DCFs against a relevant Gram-positive bacterium, S. aureus (strain Mu50, Table 2).

Globally, the selected DCFs are slightly less active against $S$. aureus than against $P$. aeruginosa, except for DCF3B that displayed the best activities at similar concentrations for both strains. Interestingly, the two functional modules $\mathbf{3 A}$ and $3 \mathbf{B}$ did not show any antibiofilm activity $\left(\mathrm{BBIC}_{50}>1 \mathrm{mM}\right)$ whereas their corresponding DCFs inhibited $S$. aureus biofilm formation. Even more interesting was the fact that the $\mathrm{BBIC}_{50}$ of DCF3A was lower than its $\mathrm{MIC}_{50}$ suggesting an antibiofilm mechanism that is not due to growth inhibition.

Hemolytic activities of the 3 best DCFs have been measured on human red blood cells in the same concentration range than the antibiofilm assays realized in our study. These experiments show that DCF3A and DCF3B have no detectable hemolytic activities (3 independent experiments on blood samples of 3 different donors). DCF3C displayed only $2 \%$ hemolytic activity at the highest tested concentration $\left(0.5 \mathrm{mg} \cdot \mathrm{mL}^{-1}\right)$, which is much higher than the antibiofilm activity

\section{Conclusion}

In this study, we generated a large number of Dynamic Constitutional Frameworks (DCFs), thanks to an easy synthesis method based on dynamic chemistry. The DCFs were tested against two bacterial strains $(P$. aeruginosa PAO1 and $S$. aureus Mu50) for their antibacterial, antibiofilm and biofilm disruption effects.

The main findings of this study are:

1) The functional heads play a crucial role in DCF's bioactivity as antibacterial agents and biofilm disruptors. Positively charged multivalent DCFs gave the best results. The nature of the cation or polycation has a dramatic impact on the antibiofilm activity.
2) DCF3B gave the best antibiofilm activity for both $P$. aeruginosa and $S$. aureus using the standard crystal violet assay. Using a more advanced in vitro biofilm model of chronic wound infection, DCF3C was found significantly superior than the other DCFs.

3) Some of the functional heads did not display any or only poor activity by themselves but their corresponding DCFs had significant antibiofilm activity. These results showed that the central core of the DCFs (DCF0), although biologically inactive, could play a key role, probably by properly displaying the functional heads. This feature was particularly important for DCF3C whose functional module 3C had neither antibiofilm nor bacterial growth inhibition activities, which showed that the DCF itself displayed the antibiofilm activity, and not its subcomponents, even if released under acidic conditions.

4) The mode of action of the other cationic materials was mainly bactericidal, although some of them displayed antibiofilm activities at concentrations lower than those required for growth inhibition. The latter feature is rare and demonstrates that the specific structures of the best DCFs could interact with the biofilm elements themselves and prevented the biofilm growth.

Our study shows that dynamic combinatorial chemistry can enable the quick identification of novel materials with highly challenging biological properties such as biofilm inhibition growth or mature biofilm disruption. Of course, further studies are still required in view of the development of materials as commercially available antibiofilm agents: For instance, the bioavailability and the stability in biological media have still to be determined.

Such a discovery approach could also be extrapolated for the identification and development of dynamic materials for other important biomedical applications.

\section{Acknowledgements}

We thank Mihaela Balan for measuring part of the NMR spectra, Laura Ursu for AFM experiments and Lilia Clima and Mariana Pinteala for the continuous support of our work. This research was funded by of Ministry of Research and Innovation, CNCSUEFISCDI, project number SupraChem Lab PN-III-P3-3.6H2020-2016-0011 and UNamur FSR PhD grant to AC.

Keywords: biofilms - Dynamic Constitutional Chemistry • Antibacterial agents $\bullet$ antibiofilm agents $\bullet$ crystal violet

\section{References}

[1] R. M. Donlan, Emerg. Infect. Dis. 2002, 8, 881-890.

[2] a) J. Azeredo, N. F. Azevedo, R. Briandet, N. Cerca, T. Coenye, A. R. Costa M. Desvaux, G. Di Bonaventura, M. Hebraud, Z. Jaglic, M. Kacaniova, S. Knochel, A. Lourenco, F. Mergulhao, R. L. Meyer, G. Nychas, M. Simoes, O. Tresse, C. Sternberg, Crit. Rev. Microbiol. 2017, 43, 313-351; b) C. N. Srivastava A., Kumar S. , in Biofilms in Human Diseases: Treatment and Control (Ed.: C. N. Kumar S., Singh L., Hashmi M., Varma A. ), Springer, Cham., 2019; c) Z. Khatoon, C. D. McTiernan, E. J. Suuronen, T. F. Mah, E. I. Alarcon, Heliyon 2018, 4, e01067.d) S. E. Rossiter, M. H. Fletcher, W. M. Wuest, Chem. Rev. 2017, 117(19), 12415-12474.

[3] H. Van Acker, P. Van Dijck, T. Coenye, Trends Microbiol. 2014, 22, 326333.

[4] a) T. Bjarnsholt, O. Ciofu, S. Molin, M. Givskov, N. Hoiby, Nat. Rev. Drug Discov. 2013, 12, 791-808; b) K. P. Rumbaugh, Biofilm 2020, Jun 5, 100028.

[5] A. D. Verderosa, M. Totsika, K. E. Fairfull-Smith, Front. Chem. 2019, 7, 824 
[6] a) T. Bottcher, I. Kolodkin-Gal, R. Kolter, R. Losick, J. Clardy, J. Am. Chem. Soc. 2013, 135, 2927-2930; b) L. Gao, M. Li, S. Ehrmann, Z. Tu, R. Haag Angew. Chem. Int. Ed. Engl. 2019, 58, 3645-3649; c) A. Dragos, H. Kiesewalter, M. Martin, C. Y. Hsu, R. Hartmann, T. Wechsler, C. Eriksen, S. Brix, K. Drescher, N. Stanley-Wall, R. Kummerli, A. T. Kovacs, Curr Biol. 2018, 28, 1903-1913 e1905; d) M. C Jennings, K. P. C. Minbiole, W.M Wuest, ACS Infect. Dis. 2015, 1, 288-303

[7] K. Drescher, C. D. Nadell, H. A. Stone, N. S. Wingreen, B. L. Bassler, Curr. Biol. 2014, 24, 50-55.

[8] a) R. Joseph, D. Kaizerman, I. M. Herzog, M. Hadar, M. Feldman, M. Fridman, Y. Cohen, Chem. Commun. 2016, 52, 10656-10659; b) R. Joseph, A. Naugolny, M. Feldman, I. M. Herzog, M. Fridman, Y. Cohen, J. Am. Chem. Soc. 2016, 138, 754-757.

[9] M. Hentzer, G. M. Teitzel, G. J. Balzer, A. Heydorn, S. Molin, M. Givskov, M. R. Parsek, J. Bacteriol. 2001, 183, 5395-5401.

[10] a) L. Clima, B. F. Craciun, G. Gavril, M. Pinteala, Polymers 2019, 11; b) D. Su, M. Coste, A. Diaconu, M. Barboiu, S. Ulrich, J. Mater. Chem. B 2020 , 8, 9385-9403; c) Y. Q. Y. Zhang, S. Ulrich, M. Barboiu, O. Ramström, Mater. Chem. Front. 2020, 4, 489-506.

[11] A. Crabbe, Y. Liu, N. Matthijs, P. Rigole, C. De La Fuente-Nunez, R. Davis, M. A. Ledesma, S. Sarker, R. Van Houdt, R. E. Hancock, T. Coenye, C. A. Nickerson, Sci. Rep. 2017, 7, 43321.

[12] a) D. Tielker, S. Hacker, R. Loris, M. Strathmann, J. Wingender, S. Wilhelm, F. Rosenau, K. E. Jaeger, Microbiology 2005, 151, 1313-1323; b) C. Chemani, A. Imberty, S. de Bentzmann, M. Pierre, M. Wimmerova, B. P. Guery, K. Faure, Infect. Immun. 2009, 77, 2065-2075; c) S. P. Diggle, R. E. Stacey, C. Dodd, M. Camara, P. Williams, K. Winzer, Environ. Microbiol. 2006, 8, 1095-1104; d) J. L. Reymond, T. Darbre, Org. Biomol. Chem. 2012, 10, 1483-1492.

[13] a) R. Catana, M. Barboiu, I. Moleavin, L. Clima, A. Rotaru, E. L. Ursu, M. Pinteala, Chem. Commun. 2015, 51, 2021-2024; b) I. A. Turin-Moleavin, F. Doroftei, A. Coroaba, D. Peptanariu, M. Pinteala, A. Salic, M. Barboiu, Org. Biomol. Chem. 2015, 13, 9005-9011.

[14] a) R. E. Fitzsimmons, H. Uludag, Acta Biomater. 2012, 8, 3941-3955; b) M. A. C. Maria G. Carneiro-da-Cunha, Bartolomeu W.S. Souza, José A. Teixeira, António A. Vicente,, Carbohydr. Polym. 2011, 85, 522-528; c) L. Marin, D. Ailincai, M. Calin, D. Stan, C. A. Constantinescu, L. Ursu, F. Doroftei, M. Pinteala, B. C. Simionescu, M. Barboiu, ACS Biomater. Sci. Eng. 2016, 2, 104-111.

[15] I. Vandecandelaere, H. Van Acker, T. Coenye, Methods Mol. Biol. 2016, 1333, 53-66

[16] a) Y. Morita, J. Tomida, Y. Kawamura, Front. Microbiol. 2014, 4, 422; b) L. R. Mulcahy, V. M. Isabella, K. Lewis, Microb. Ecol. 2014, 68, 1-12.

[17] a) O. Orgad, Y. Oren, S. L. Walker, M. Herzberg, Biofouling 2011, 27, 787 798; b) A. Boyd, A. M. Chakrabarty, J. Ind. Microbiol. 1995, 15, 162-168.

[18] a) S. S. Branda, S. Vik, L. Friedman, R. Kolter, Trends Microbiol. 2005, 13, 20-26; b) H. C. Flemming, T. R. Neu, D. J. Wozniak, J. Bacteriol. 2007 189, 7945-7947.

[19] a) I. Di Bonaventura, S. Baeriswyl, A. Capecchi, B. H. Gan, X. Jin, T. N. Siriwardena, R. He, T. Kohler, A. Pompilio, G. Di Bonaventura, C. van Delden, S. Javor, J. L. Reymond, Chem. Commun. 2018, 54, 5130-5133 b) G. Michaud, R. Visini, M. Bergmann, G. Salerno, R. Bosco, E. Gillon, B. Richichi, C. Nativi, A. Imberty, A. Stocker, T. Darbre, J. L. Reymond, Chem. Sci. 2016, 7, 166-182.

[20] a) X. H. Li, J. H. Lee, J. Microbiol. 2017, 55, 753-766; b) N. Rabin, Y. Zheng, C. Opoku-Temeng, Y. Du, E. Bonsu, H. O. Sintim, Future Med. Chem. 2015, 7, 493-512.

[21] G. Brackman, M.J. Garcia-Fernandez, J. Lenoir, L. De Meyer, J.P. Remon, T. De Beer, A. Concheiro, C. Alvarez-Lorenzo, T. Coenye. Macromol. Biosci. 2016, 16, 859-69. 


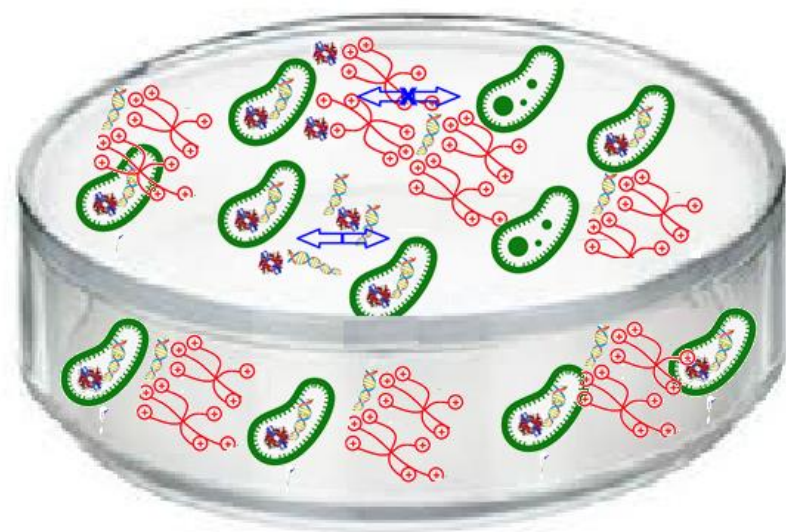

Dynamic constitutional frameworks are expressed in the presence of bacteria templating from dynamic covalent libraries made of aromatic cores, PEGylated connectors and ionic heads. This templated DCFs further translates into the multivalent presentation of cationic heads, subsequently promoting antibacterial and antibiofilm activities.

Institute and/or researcher Twitter usernames: Synergistic multivalent dynamic constitutional frameworks with antibacterial activity and antibiofilm disruption. Fruitfull collabaoration between @MihailBarboiu @CNRS_OccitaniE, @tcoenye @ipm_ugent and Stephane Vincent, Universite de Namuur 